\title{
TELETRABALHO NA ADMINISTRAÇÃO PÚBLICA: INSTRUMENTO DE SUPORTE À IDENTIFICAÇÃO DE ADAPTABILIDADE DE TAREFAS E PESSOAS
}

Patrícia Paranhos de Oliveira Carneval (UFF) patriciacarneval@id.uff.br

Suzana Dantas Hecksher (UFF) suzanahecksher@id.uff.br

\section{Resumo}

O avanço das tecnologias de informação e comunicação, a dificuldade na mobilidade urbana, e restrições de recursos nas instituições públicas favorecem a adoção do teletrabalho, ou trabalho remoto. Esta modalidade de trabalho, mesmo em tempo parcial, associa flexibilização de local e horário à jornada de trabalho. A principal contribuição desta pesquisa foi desenvolver um método de identificação de tarefas teletrabalháveis, capaz de apoiar a implantação sistematizada do teletrabalho na instituição federal de ensino superior estudada. Para o desenvolvimento, foram percorridas as seguintes etapas: (a) Pesquisa bibliográfica para identificar fatores críticos de sucesso na implantação do teletrabalho associados às pessoas, tarefas, tecnologia e organização; (b) Mapeamento de experiências de teletrabalho e instrumentos regulatórios existentes na administração pública; (c) Desenvolvimento da proposta inicial do método e pré-teste num setor; (d) Desenvolvimento do método, incluindo roteiro de questões, indicadores e critérios para análise da aderência entre a situação analisada (pessoa-tarefas) e os fatores críticos de sucesso na literatura; (e) Construção de ferramenta que classifica a situação analisada como indicada para teletrabalho ou aponta as pendências para viabilizar a adoção; (f) Aplicação em cinco setores, três deles com tarefas mapeadas e uso do Sistema Eletrônico de Informação (SEI) e dois sem processos no SEI. (g) Análise dos resultados. Além do método, a pesquisa evidenciou diretrizes gerais que favorecem o sucesso da adoção sistematizada do teletrabalho na instituição, bem como indicou que a aplicação do método torna as características das tarefas mais evidentes, sinalizando pontos onde é preciso avançar para facilitar a adaptação ao teletrabalho.

Palavras-Chaves: Teletrabalho; Trabalho remoto; Organização do trabalho; Serviço Público.

\section{Introdução}

A sociedade demanda, crescentemente, por serviços públicos de qualidade e àgeis. A utilização das tecnologias da informação e comunicação (TICs) viabiliza a prestação de serviços digitais, mais rapidamente, com segurança e menor custo. Diversas esferas da 
administração pública avançaram na utilização de TICs, permitindo mais serviços públicos remotos. Todavia, apesar do avanço tecnológico, ainda é incomum o teletrabalho para servidores públicos.

A maioria dos serviços públicos se concentra nas grandes cidades, onde encontram-se problemas como dificuldade de mobilidade, alto custo de vida, restrições orçamentárias para investimento e manutenção de instalações públicas, dentre outros. Este cenário, aliado às transformações políticas, econômicas, sociais e tecnológicas, amplia a viabilidade da adoção do teletrabalho.

Outras expressões são encontradas na literatura para o teletrabalho, tais como: trabalho remoto, trabalho à distância, entre outros. Segundo Nilles (1998), teletrabalho é qualquer forma de substituição do deslocamento relacionado com a atividade de trabalho por tecnologia de informação ou, de forma mais gráfica, a possibilidade de enviar o trabalho ao trabalhador, em vez de enviar o trabalhador ao trabalho.

Na esfera privada, a alteração da Consolidação de Leis do Trabalho (CLT), através da Lei $\mathrm{n}^{\mathrm{o}} 12.551 / 2011$, equiparou o teletrabalho ao trabalho realizado no estabelecimento do empregador. No setor público, a prática do teletrabalho ainda é recente e desenvolvida através de projetos-piloto, como, por exemplo, no Serviço Federal de Processamento de Dados (SERPRO).

O contexto específico desta pesquisa inclui o Processo Eletrônico Nacional (PEN), iniciativa do Governo Federal para construção de infraestrutura pública de processos e documentos administrativos eletrônicos, a partir de 2015, objetivando melhorar o desempenho dos processos no setor público, com ganhos em agilidade, produtividade, transparência, satisfação do usuário e redução de custos. Uma das entregas é o Sistema Eletrônico de Informações (SEI), que passou a ser utilizado na Instituição Pública Federal de Ensino Superior objeto de estudo da pesquisa em 2017. A utilização deste sistema potencializa a adoção do teletrabalho, por toda análise de processos administrativos ocorrer via TICs, sem movimentação física.

Nesta Instituição, o teletrabalho já é realizado, tanto entre servidores técnico administrativos (elaboração de relatórios, resposta a e-mails, etc.), quanto entre servidores docentes (lançamento de notas, preparação de aulas, etc.), porém ocorre de maneira informal, sem planejamento nem controle sistematizados. 
A pesquisa foi motivada pelo reconhecimento da necessidade do desenvolvimento de um método de identificação de tarefas teletrabalháveis, de forma a orientar a adoção sistematizada e planejada do teletrabalho. Com base na análise de experiências nacionais e internacionais de adoção, foram discutidas formas de organização do trabalho remoto, fatores críticos que favorecem ou dificultam sua adoção e fatores relacionados à base legal. Considerando as diferenças entre as esferas privada e pública, o método foi construído e experimentado, através da pesquisa de campo, em setores de uma universidade pública brasileira.

Sendo assim, para alcançar o objetivo geral, os seguintes objetivos específicos foram traçados:

- Identificar fatores críticos (pessoais, características das tarefas, tecnológicos e organizacionais) relacionados ao sucesso na implantação do teletrabalho;

- Analisar a existência de experiências de teletrabalho no âmbito da Administração Pública Brasileira;

- Desenvolver método de identificação de tarefas teletrabalháveis, com base nos fatores críticos;

- Propor diretrizes para aplicação do método e implantação do teletrabalho na instituição pública de ensino superior.

\section{Referencial teórico}

O teletrabalho têm prós e contras. Uma investigação realizada por empresas de telecomunicações mostrou que o teletrabalho produz um efeito positivo no desempenho. Este regime de trabalho economiza o tempo de deslocamento, permite horários flexíveis e uma maior liberdade, contudo reduz as oportunidades de trabalho em equipe e a interação social, tendo os empregadores mais dificuldade em gerir os trabalhadores (PINUD, 2015).

Mokhtarian e Salomon, que estão entre os autores com maior volume de publicações sobre o tema, buscaram determinar os fatores críticos de sucesso significativos na adoção do teletrabalho pelas organizações. Mokhtarian e Salomon (1994) salientam que a percepção do teletrabalho ser ou não uma estratégia bem-sucedida depende fortemente de expectativas prévias de cada indivíduo. Em outro estudo, os autores identificaram restrições que podem potencialmente inibir a adoção do teletrabalho: falta de conhecimento sobre o tema, trabalho não adaptável, falta de apoio da gerência, indisponibilidade de tecnologia e custo 
(MOKHTARIAN E SALOMON, 1996). Estes estudos apontam para fatores relacionados às tarefas realizadas no trabalho, às características pessoais dos trabalhadores, à estrutura organizacional da empresa e à tecnologia necessária para o teletrabalho.

O’Neill et al. (2009) apontam que os preditores pessoais de sucesso para teletrabalhadores tendem a três categoria: capacidade de separar vida pessoal da profissional, capacidade de trabalhar sem supervisão constante e capacidade de superar a ameaça de isolamento. Sugerem que a seleção de teletrabalhadores deve ser criteriosa pelas organizações. Apontam ainda certos fatores situacionais (número de filhos, por exemplo) e de característica do trabalho (autonomia e complexidade) como importantes na implantação do teletrabalho.

Turetken et al. (2011) investigaram como algumas características relacionadas às pessoas e às tarefas impactam no sucesso do teletrabalho. As variáveis investigadas foram tempo de permanência no emprego atual, experiência de trabalho, habilidades de comunicação, independência da tarefa, mensurabilidade das saídas do trabalho e variedade da tarefa. Essas variáveis foram consideradas por serem identificáveis e mensuráveis. Classificaram essas variáveis em quatro dimensões dos fatores críticos de sucesso (pessoas, tarefas, organização e tecnologia). Como conclusão, destacaram que o teletrabalho é um subproduto importante da chamada revolução das TICs. E, assim como em outras aplicações de tecnologia nas organizações, boas práticas de gerenciamento, mais do que a tecnologia em si, irão eventualmente determinar o sucesso do teletrabalho.

No setor privado, em 13 de julho de 2017, entrou em vigor a Lei $\mathrm{n}^{\mathrm{o}}$ 13.467, regulamentando o teletrabalho em organizações privadas no Brasil. No setor público, ainda não há lei aprovada regulamentando o teletrabalho. Em 31 de agosto de 2018, o Ministério do Planejamento, Desenvolvimento e Gestão (MP) publicou a Instrução Normativa (IN) $\mathrm{n}^{\mathrm{o}} 1$, orientando a implantação do Programa de Gestão pelos órgãos públicos integrantes do Sistema de Pessoal Civil da Administração Federal (Sipec). Esta IN cria procedimentos e critérios gerais para a dispensa do controle de frequência dos servidores participantes do programa, com a implementação do teletrabalho de forma facultativa, ocorrendo em função da conveniência e interesse do serviço público. Alguns critérios são de atividades mensuráveis e obrigatoriedade de avaliação da produtividade e dos resultados das unidades que optarem pelo programa. São previstas três modalidades, conforme quadro abaixo (Quadro 1). 
Quadro 1 - Modalidades de teletrabalho

\begin{tabular}{|c|c|}
\hline MODALIDADE & CARACTERÍSTICAS \\
\hline Semipresencial & $\begin{array}{c}\text { O servidor executa suas atribuições parcialmente fora das } \\
\text { dependências da unidade em alguns dias por semana ou em } \\
\text { turnos por dia. }\end{array}$ \\
\hline Teletrabalho & $\begin{array}{l}\text { O servidor executa suas atribuições integralmente fora das } \\
\text { dependências da unidade. }\end{array}$ \\
\hline Por tarefa & $\begin{array}{c}\text { O servidor executa tarefa determinada e com prazo definido } \\
\text { fora das dependências da unidade. }\end{array}$ \\
\hline
\end{tabular}

Segundo o Ministério do Planejamento, Desenvolvimento e Gestão (2018), alguns órgãos da administração pública já possuem pilotos de implantação de teletrabalho, dentre eles o Ministério da Transparência e Controladoria Geral da União (CGU) e a Advocacia Geral da União (AGU). Essas experiências indicam uma possibilidade de adesão desta modalidade de trabalho, mesmo sem uma lei geral do teletrabalho no setor público até o momento. Para tal, os órgãos públicos utilizam normas de direito administrativo - decretos, resoluções, dentre outros - para disciplinar o teletrabalho, em sua grande maioria baseados no princípio da eficiência, ou buscando redução de custo para a administração pública.

Os quadros (Quadro 2, Quadro 3 e Quadro 4) a seguir apresentam alguns instrumentos regulatórios sobre teletrabalho já utilizados na administração pública brasileira, analisando-os de forma a levantar variáveis quanto às regras gerais, vedações e produtividade exigida. Em todos, o custo e responsabilidade com a infraestrutura tecnológica são a cargo do servidor. 
Quadro 2 - Instrumentos regulatórios - regras gerais

\begin{tabular}{|c|c|}
\hline \multicolumn{2}{|c|}{ Regras gerais } \\
\hline$\underset{\&}{2}$ & $\begin{array}{l}\text { Facultativo; } \\
\text { Solicitação formal; Termo de compromisso; Mínimo de } 1 \text { ano ininterrupto no Órgão; } \\
\text { máximo de } 50 \% \text { da força de trabalho; ciclo bienal. }\end{array}$ \\
\hline$\underset{\varrho}{\varrho}$ & Máximo de $40 \%$ da força de trabalho da unidade; ciclo semestral. \\
\hline$\frac{n}{\frac{\pi}{\alpha}}$ & $\begin{array}{l}\text { Facultativo; } \\
\text { Solicitação formal; Plano de trabalho; Duração de no mínimo } 6 \text { e no máximo } 24 \\
\text { meses. }\end{array}$ \\
\hline$\underset{U}{己}$ & Máximo de $20 \%$ dos servidores da unidade. \\
\hline 空 & Facultativa; Acordo formal; Termo de adesão. \\
\hline
\end{tabular}

Fonte: Os autores

Quadro 3 - Instrumentos regulatórios - produtividade

\begin{tabular}{|c|c|}
\hline \multicolumn{2}{|c|}{ Produtividade } \\
\hline$\underset{\&}{2}$ & $15 \%$ a mais do que o serviço presencial / avaliação semestral. \\
\hline 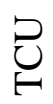 & Superior ao serviço presencial / avaliação semestral. \\
\hline$\frac{n}{\frac{1}{\alpha}}$ & $15 \%$ a mais do que o serviço presencial / avaliação trimestral. \\
\hline 己 & $\begin{array}{l}\text { Superiores às metas previstas para as mesmas atividades em execução nas } \\
\text { dependências físicas do órgão. / Avaliação trimestral. }\end{array}$ \\
\hline 芒 & Avaliação anual. \\
\hline
\end{tabular}


Quadro 4 - Instrumentos regulatórios - vedações

\begin{tabular}{|c|c|}
\hline \multicolumn{2}{|c|}{ Vedações } \\
\hline$\underset{\&}{Z}$ & $\begin{array}{l}\text { Estar em estágio probatório; Ocupante ou substituto em cargo em comissão, função } \\
\text { comissionada, função gratificada ou assemelhados; já ter sido excluído do trabalho } \\
\text { remoto por descumprimento dos deveres. }\end{array}$ \\
\hline$\underset{\varphi}{己}$ & $\begin{array}{l}\text { Conceito inferior a "A" na avaliação de desempenho profissional; em estágio } \\
\text { probatório; função de confiança de natureza direção; sindicância ou processo } \\
\text { disciplinar com culpabilidade nos últimos } 24 \text { meses. }\end{array}$ \\
\hline$\frac{n}{\frac{1}{\alpha}}$ & $\begin{array}{l}\text { Estágio probatório; atividades com presença física indispensável; nomeado ou } \\
\text { designado para cargo ou função de chefia na RFB; sindicância ou processo disciplinar } \\
\text { com culpabilidade nos últimos } 24 \text { meses; já ter sido excluído do trabalho remoto por } \\
\text { não atingimento de metas. }\end{array}$ \\
\hline 己 & $\begin{array}{l}\text { Ocupantes de cargo em comissão do Grupo-Direção e Assessoramento Superiores - } \\
\text { DAS ou de Natureza Especial ou de função gratificada; que tenham sido apenados em } \\
\text { procedimento disciplinar nos dois anos anteriores à data de solicitação para participar } \\
\text { do PGD; com menos de seis meses de exercício na unidade organizacional. }\end{array}$ \\
\hline$\frac{\partial}{\tilde{I}}$ & $\begin{array}{l}\text { Contraindicação por motivo de saúde comprovada em perícia médica; não disponham } \\
\text { de recursos tecnológicos necessários. }\end{array}$ \\
\hline
\end{tabular}

Fonte: Os autores

Segundo Dalloul (2018), corroborando ao princípio da eficiência, o teletrabalho no setor público fica atrelado aos casos onde é possível medir a produtividade dos servidores. Observa-se que muitos instrumentos normativos tratam o teletrabalho como vantagem a ser concedida ao servidor por exigir contraprestação, e não como uma mera forma de prestação de serviço. O regime de teletrabalho no serviço público destoa do encontrado no setor privado (exigência de maior produtividade e por repassar os custos da infraestrutura necessária ao servidor).

\section{Metodologia}

A pesquisa foi realizada em uma universidade pública, criada em 1960, presente em 9 municípios. Possui 41 Unidades de Ensino atendendo a mais de 50.000 discentes e seu corpo funcional conta com cerca de 3400 servidores docentes, 4400 servidores técnicoadministrativos, além de empresas terceirizadas para prestação de serviços de apoio.

Para desenvolvimento do método de identificação de tarefas teletrabalháveis foram percorridas as seguintes etapas: 
a) pesquisa bibliográfica para identificar fatores críticos de sucesso na implantação do teletrabalho associados às pessoas, tarefas, tecnologia e organização;

b) mapeamento de experiências de teletrabalho e instrumentos regulatórios já existentes na administração pública;

c) desenvolvimento da proposta inicial do método e pré-teste em um setor;

d) desenvolvimento do método, incluindo roteiro de questões, indicadores e critérios para análise da aderência entre a situação analisada (pessoa-tarefas) e os fatores críticos de sucesso para o teletrabalho;

e) construção de ferramenta que estrutura a aplicação do método de análise e classifica a situação analisada como indicada para teletrabalho ou aponta pendências para viabilizar a adoção;

f) aplicação em cinco setores, três deles com tarefas mapeadas no SEI e dois setores sem processos no SEI. Opção por diferentes cenários de tecnologias, considerando que o SEI é um facilitador para o teletrabalho, mas outros sistemas e ferramentas tecnológicas da instituição também possibilitam a execução das tarefas remotamente;

g) Análise dos resultados e elaboração de diretrizes para implantação.

$\mathrm{O}$ instrumento de coleta de dados foi a entrevista, incluindo perguntas abertas e fechadas, com roteiro estruturado para identificação de tarefas teletrabalháveis. Sua confecção foi baseada nos questionários e entrevistas desenvolvidos pelos seguintes autores: Sims et al. (1976); Fritz, Narasimhan e Rhee (1998); Staples, Hulland e Higgins (1999); WatsonManheim, Piramuthu e Narasimhan (2000); Neufeld e Fang (2005); Garrett e Danziger (2007) e Turetken et al. (2011), além de inclusões de novas questões. A entrevista foi estruturada em cinco blocos, descritos no quadro abaixo (Quadro 5).

Quadro 5 - Estrutura da entrevista

\begin{tabular}{|c|c|}
\hline BLOCOS & OBJETIVOS \\
\hline 1 & Buscar informações sobre o perfil do entrevistado. \\
\hline 2 & Levantar características das tarefas realizadas pelo respondente. \\
\hline 3 & Investigar sobre a habilidade do entrevistado com tecnologia. \\
\hline 4 & Avaliar as condições de trabalho na Instituição. \\
\hline 5 & Averiguar sobre o interesse e experiência dos respondentes em teletrabalhar. \\
\hline
\end{tabular}


O instrumento de avaliação de tarefas teletrabalháveis foi elaborado pela criação de indicadores e critérios relacionados aos fatores críticos de sucesso para o teletrabalho, com base na pesquisa bibliográfica. As fontes para análise de cada indicador foram as questões feitas na entrevista, ora analisadas individualmente, ora em grupos de questões relacionadas ao indicador. Para cada indicador foi criado um critério (ou fórmula) de avaliação, além de classificá-los em não conclusivo, preditivo ou restritivo. Foram considerados não conclusivos os indicadores cujo conjunto de fatores associados não encontrava nas referências uma correlação clara com o sucesso ou insucesso na adoção do teletrabalho. Os fatores não conclusivos são registrados para caracterização e acompanhamento posterior de resultados. Foram classificados como preditivos fatores que a literatura indica como relacionados ao sucesso na adoção do teletrabalho. Foram classificados como restritivos fatores considerados como necessários para viabilizar a adoção ao teletrabalho.

Os quadros a seguir apresentam os indicadores criados, explicitando os temas abordados pelas questões relacionadas a cada indicador, a classificação do indicador e os critérios de predição ou restrição.

Quadro 6 - Indicadores relacionados às pessoas

\begin{tabular}{|l|l|l|}
\hline Indicadores & Temas das questões relacionadas & Classificação \\
\hline Perfil & Cargo / Sexo / Idade / Dependentes & Não conclusivo \\
\hline $\begin{array}{l}\text { Experiência } \\
\text { profissional }\end{array}$ & $\begin{array}{l}\text { Experiência total de trabalho e } \\
\text { experiência seu setor atual }\end{array}$ & $\begin{array}{l}\text { Preditivo } \\
\text { (quanto maior, melhor) }\end{array}$ \\
\hline $\begin{array}{l}\text { Tempo de serviço na } \\
\text { instituição }\end{array}$ & Tempo de trabalho na sua Instituição & $\begin{array}{l}\text { Restritivo } \\
\text { (período de estágio } \\
\text { probatório concluído) }\end{array}$ \\
\hline
\end{tabular}

Fonte: Os autores

Quadro 7 - Indicadores relacionados às condições de trabalho na instituição

\begin{tabular}{|l|l|l|}
\hline Indicadores & Temas das questões relacionadas & Classificação \\
\hline \multirow{5}{*}{ Condições de trabalho } & Condições do local de trabalho na & \\
& instituição quanto a interrupções, & \\
distrações, ruído, limpeza, iluminação, & ventilação, mobiliário, equipamentos e & Não conclusivo \\
& ferramentas, materiais, infraestrutura & \\
& de comunicação e tecnologia de & \\
& informação e acesso às informações. & \\
\hline
\end{tabular}


Quadro 8 - Indicadores relacionados à tecnologia

\begin{tabular}{|l|l|l|}
\hline Indicadores & Temas das questões relacionadas & Classificação \\
\hline $\begin{array}{l}\text { Capacidade técnica - } \\
\text { hardware e software }\end{array}$ & $\begin{array}{l}\text { Qual sua capacidade de resolver um } \\
\text { problema técnico de hardware ou } \\
\text { software? }\end{array}$ & Não conclusivo \\
\hline $\begin{array}{l}\text { Habilidade de } \\
\text { utilização } \\
\begin{array}{l}\text { computador, } \\
\text { softwares e sistemas }\end{array}\end{array}$ & $\begin{array}{l}\text { Qual sua habilidade para utilizar o } \\
\text { computador, softwares e sistemas } \\
\text { necessários para executar suas tarefas? }\end{array}$ & $\begin{array}{l}\text { Restritivo } \\
\text { (habilidade boa ou muito } \\
\text { boa) }\end{array}$ \\
\hline
\end{tabular}

Fonte: Os autores

Quadro 9 - Indicadores da percepção do servidor quanto ao teletrabalho

\begin{tabular}{|c|c|c|}
\hline Indicadores & Fontes & Classificação \\
\hline $\begin{array}{l}\text { Interesse } \\
\text { teletrabalhar }\end{array}$ & $\begin{array}{l}\text { Você gostaria de realizar sua jornada } \\
\text { de trabalho fora do escritório da } \\
\text { Instituição? Você acredita que seria } \\
\text { vantajoso trabalhar parcialmente de } \\
\text { casa (financeiramente, socialmente } \\
\text { etc.)? Em termos de saúde física, } \\
\text { mental e segurança do trabalho, você } \\
\text { considera que seria vantajoso trabalhar } \\
\text { parcialmente de casa? }\end{array}$ & $\begin{array}{l}\text { Restritivo } \\
\text { (interesse em trabalhar } \\
\text { pelo menos parcialmente } \\
\text { de forma remota e } \\
\text { percepção positiva } \\
\text { quanto aos impactos) }\end{array}$ \\
\hline Recursos & $\begin{array}{l}\text { Você possui recursos próprios } \\
\text { (computador, internet, mobiliário, } \\
\text { telefone etc.) necessários para realizar } \\
\text { parte do seu trabalho em casa? Você } \\
\text { estaria disposto a investir e arcar com } \\
\text { os custos de recursos próprios } \\
\text { (computador, internet, mobiliário, } \\
\text { telefone etc.) necessários para realizar } \\
\text { seu trabalho em casa? }\end{array}$ & $\begin{array}{l}\text { Restritivo } \\
\text { (Disponibilidade de } \\
\text { recursos pessoais e para } \\
\text { investir e custear os } \\
\text { recursos necessários ao } \\
\text { trabalho remoto) }\end{array}$ \\
\hline
\end{tabular}


Quadro 10 - Indicadores relacionados às tarefas

\begin{tabular}{|c|c|c|}
\hline Indicadores & Temas das questões relacionadas & Classificação \\
\hline $\begin{array}{l}\text { Variedade } \\
\text { similaridade }\end{array}$ & $\begin{array}{l}\text { As tarefas que você realiza nos seus } \\
\text { dias de trabalho são similares? Há } \\
\text { oportunidade de fazer várias tarefas } \\
\text { diferentes no seu trabalho? }\end{array}$ & $\begin{array}{l}\text { Preditivo } \\
\text { (quanto menos } \\
\text { variedade, melhor) }\end{array}$ \\
\hline Autonomia & $\begin{array}{l}\text { Você possui autonomia para executar } \\
\text { suas tarefas sozinho? Você pode agir } \\
\text { de forma independente do seu } \\
\text { supervisor no desempenho das suas } \\
\text { tarefas? }\end{array}$ & $\begin{array}{l}\text { Restritivo } \\
\text { (sim, para a maior parte } \\
\text { das tarefas) }\end{array}$ \\
\hline Acesso à informação & $\begin{array}{l}\text { Você possui informações suficientes } \\
\text { para realizar suas tarefas? }\end{array}$ & $\begin{array}{l}\text { Restritivo } \\
\text { (sim, para a maior parte } \\
\text { das tarefas) }\end{array}$ \\
\hline $\begin{array}{l}\text { Necessidade de } \\
\text { interação presencial } \\
\text { para execução das } \\
\text { tarefas }\end{array}$ & $\begin{array}{l}\text { Parte da jornada de trabalho em } \\
\text { tarefas que necessitam de interação } \\
\text { presencial com outras pessoas. } \\
\text { Distribuição de percentual de tempo } \\
\text { de cada processos de trabalho em } \\
\text { tarefas executados sem interação, } \\
\text { com interação remota (telefone, e- } \\
\text { mail etc.) e com interação presencial } \\
\text { com outras pessoas. }\end{array}$ & $\begin{array}{l}\text { Restritivo } \\
\text { (maior parte do tempo } \\
\text { em tarefas sem } \\
\text { exigência de interação } \\
\text { presencial) }\end{array}$ \\
\hline $\begin{array}{l}\text { Definição de } \\
\text { responsabilidades }\end{array}$ & $\begin{array}{l}\text { Suas responsabilidades estão } \\
\text { claramente definidas? }\end{array}$ & $\begin{array}{l}\text { Restritivo } \\
\text { (sim, para a maior parte } \\
\text { das tarefas) }\end{array}$ \\
\hline $\begin{array}{l}\text { Padronização de } \\
\text { processos de trabalho }\end{array}$ & $\begin{array}{l}\text { Existe uma sequência de etapas de } \\
\text { como executar este processo, com } \\
\text { procedimentos } \\
\text { estabelecidas? }\end{array}$ & $\begin{array}{l}\text { Restritivo } \\
\text { (sim, para a maior parte } \\
\text { das tarefas) }\end{array}$ \\
\hline $\begin{array}{l}\text { Mensurabilidade de } \\
\text { processos de trabalho }\end{array}$ & $\begin{array}{l}\text { Os resultados deste processo são } \\
\text { claramente visíveis e mensuráveis? }\end{array}$ & $\begin{array}{l}\text { Restritivo } \\
\text { (sim, para a maior parte } \\
\text { das tarefas) }\end{array}$ \\
\hline $\begin{array}{lr}\text { Controle } & \text { de } \\
\text { resultados } & \text { dos } \\
\text { processos de trabalho }\end{array}$ & $\begin{array}{l}\text { Atualmente, há indicadores de } \\
\text { resultados deste processo que são } \\
\text { acompanhados por sua chefia? }\end{array}$ & $\begin{array}{l}\text { Restritivo } \\
\text { (sim, para a maior parte } \\
\text { das tarefas) }\end{array}$ \\
\hline $\begin{array}{lr}\text { Percepção } & \text { de } \\
\text { viabilidade } & \text { para } \\
\text { trabalho remoto } & \end{array}$ & $\begin{array}{l}\text { Na sua avaliação, é possível realizar } \\
\text { este processo remotamente, fora da } \\
\text { Instituição? }\end{array}$ & $\begin{array}{ll}\text { Restritivo } & \\
\text { (maior } & \text { parte dos } \\
\text { processos } & \text { considerados } \\
\text { possível, } & \text { mesmo que } \\
\text { com } & \text { pequenas } \\
\text { adaptações) } & \end{array}$ \\
\hline
\end{tabular}

Fonte: Os autores

As entrevistas foram realizadas presencialmente, pela primeira autora, em dezembro de 2018. Foram entrevistados cinco servidores, abrangendo cinco setores da Instituição 
Federal de Ensino Superior estudada, cujas características estão resumidas a seguir (Quadro $11)$.

Quadro 11 - Servidores e setores entrevistados

\begin{tabular}{|c|c|c|c|c|}
\hline SETOR & $\begin{array}{l}\text { SERVIDORES } \\
\text { ENTREVISTADOS }\end{array}$ & ATIVIDADE PRINCIPAIS & $\begin{array}{c}\text { SETOR SUBORDINADO } \\
\text { À: }\end{array}$ & $\begin{array}{l}\text { UTILIZA O } \\
\text { SEI? }\end{array}$ \\
\hline 1 & Servidora A e servidora B. & $\begin{array}{c}\text { Analisa processos para licenças e afastamentos para capacitação tanto } \\
\text { de docentes, quanto de técnicos administrativos. }\end{array}$ & \begin{tabular}{|c|} 
Pró Reitoria de Gestão de \\
Pessoas (PROGEPE).
\end{tabular} & Sim \\
\hline 2 & Servidora C. & $\begin{array}{l}\text { Responsável pelo recrutamento e movimentação de servidores } \\
\text { técnicos administrativos. }\end{array}$ & $\begin{array}{c}\text { Pró Reitoria de Gestão de } \\
\text { Pessoas (PROGEPE). }\end{array}$ & Sim \\
\hline 3 & $\begin{array}{c}\text { Servidora C. (Esta } \\
\text { servidora executa suas } \\
\text { funções laborais tanto no } \\
\text { setor } 3 \text { como no } 2 \text { ). }\end{array}$ & $\begin{array}{l}\text { Este setor atua preventivamente nas questões funcionais dos } \\
\text { servidores técnicos administrativos, buscando a qualidade em suas } \\
\text { relações de trabalho. }\end{array}$ & $\begin{array}{l}\text { Pró Reitoria de Gestão de } \\
\text { Pessoas (PROGEPE). }\end{array}$ & Sim \\
\hline 4 & Servidor D. & Responsável pela coordenação de projetos com a Fundação de Apoio. & $\begin{array}{l}\text { Pró Reitoria de } \\
\text { Planejamento } \\
\text { (PROPLAN). }\end{array}$ & Não \\
\hline 5 & Servidor E. & Setor de um Departamento. & Unidade Acadêmica. & Não \\
\hline
\end{tabular}

As respostas foram avaliadas de acordo com o método descrito, onde cada situação (conjunto de fatores relativos à pessoa, tarefas, estrutura organizacional e tecnologia), ao final, foi classificada quanto à adaptabilidade ao trabalho remoto em "situação indicada ao teletrabalho" ou "situação não indicada ao teletrabalho". Em caso de não indicação, o método e o instrumento destacam os fatores que precisam ser adaptados para que passe a ser indicado como teletrabalhável. O método levou em consideração, também, a legislação e instrumentos regulatórios vigentes.

\section{Resultados e análises}

Em pergunta referente ao tipo de interação com outras pessoas utilizado para a execução da tarefa, dos 5 respondentes, todos estimaram algum percentual de tempo da jornada de trabalho para execução de tarefas que necessitam interação presencial com outras pessoas. Portanto, recomenda-se a adoção do teletrabalho de maneira parcial (alguns dias da semana) na Instituição. O teletrabalho parcial concorre para evitar aspectos negativos do trabalho remoto integral como o isolamento e a falta de visibilidade do trabalhador. Esses aspectos negativos foram estudados por O’Neill et al. (2009) e identificados na pesquisa como preocupação por alguns respondentes, que mencionaram o medo da segmentação das pessoas e a necessidade de troca de conhecimento entre os servidores do setor.

Como diretriz para implantação do teletrabalho na Instituição, sugere-se a inclusão, no termo de adesão do servidor, de todos os recursos necessários para a execução remota. Recomenda-se, conforme disposto nos instrumentos normativos de teletrabalho na 
administração pública, a medição periódica das metas acordadas no plano de teletrabalho quando da adesão ao programa pelo servidor, fazendo-se necessário o acompanhamento dos indicadores e resultados apresentados pelo teletrabalhador. Vale ressaltar que do total de 20 diferentes processos de trabalho executados pelos 5 respondentes, em 17 deles, pelo menos uma parte já é executada remotamente, ainda que esporadicamente e sem formalização junto à Instituição.

A criação e aplicação do método proposto nessa pesquisa permitem que sejam avaliados, caso a caso, os servidores e os processos de trabalho. A saída do método clarifica os casos em que uma pequena mudança pode tornar a situação (servidor-tarefas-estruturatecnologia) teletrabalhável. No caso dos servidores B e D, o impedimento seria resolvido com a criação de indicadores para avaliação dos processos de trabalho realizados remotamente.

A seguir, é apresentado um quadro resumo do método de identificação de tarefas teletrabalháveis com os dados obtidos nas entrevistas, avaliados segundo os indicadores criados, com a adaptabilidade ao teletrabalho indicada ao final (Quadro 12). 
Quadro 12 - Instrumento de avaliação de adaptabilidade ao teletrabalho

\begin{tabular}{|l|c|c|c|c|c|}
\hline Indicador & $\begin{array}{c}\text { Servidor } \\
\text { A }\end{array}$ & $\begin{array}{c}\text { Servidor } \\
\text { B }\end{array}$ & $\begin{array}{c}\text { Servidor } \\
\text { C }\end{array}$ & $\begin{array}{c}\text { Servidor } \\
\text { D }\end{array}$ & $\begin{array}{c}\text { Servidor } \\
\text { E }\end{array}$ \\
\hline Perfil & $+/-$ & $+/-$ & $+/-$ & $+/-$ & $+/-$ \\
\hline Experiência profissional & $+/-$ & $+/-$ & $+/-$ & $+/-$ & $+/-$ \\
\hline $\begin{array}{l}\text { Tempo de serviço na } \\
\text { instituição }\end{array}$ & + & + & + & + & + \\
\hline Variedade/ similaridade & $+/-$ & $+/-$ & $+/-$ & $+/-$ & $+/-$ \\
\hline Autonomia & + & + & + & + & + \\
\hline Acesso à informação interação & + & + & + & + & + \\
\hline $\begin{array}{l}\text { Necessidade de prencial para execução das } \\
\text { presentas } \\
\text { tarefas }\end{array}$ & + & + & - & + & - \\
\hline Responsabilidades definidas & + & + & + & + & - \\
\hline $\begin{array}{l}\text { Padronização de processos de } \\
\text { trabalho }\end{array}$ & + & + & + & + & + \\
\hline $\begin{array}{l}\text { Mensurabilidade de processos } \\
\text { de trabalho }\end{array}$ & + & + & + & + & + \\
\hline $\begin{array}{l}\text { Controle de resultados dos } \\
\text { processos de trabalho }\end{array}$ & + & - & + & - & - \\
\hline $\begin{array}{l}\text { Percepção de viabilidade para } \\
\text { trabalho remoto }\end{array}$ & + & + & + & + & + \\
\hline $\begin{array}{l}\text { Capacidade técnica - hardware } \\
\text { e software }\end{array}$ & $+/-$ & $+/-$ & $+/-$ & $+/-$ & $+/-$ \\
\hline $\begin{array}{l}\text { Habilidade de utilização - } \\
\text { computador, softwares } \\
\text { sistemas }\end{array}$ & + & + & + & + & + \\
\hline $\begin{array}{l}\text { Condições de trabalho } \\
\text { Interesse em teletrabalhar }\end{array}$ & + & $+/-$ & $+/-$ & $+/-$ & $+/-$ \\
\hline Recursos & $\begin{array}{c}\text { Não } \\
\text { Adaptabilidade ao teletrabalho }\end{array}$ & $\begin{array}{c}\text { Não } \\
\text { indicado }\end{array}$ & $\begin{array}{c}\text { Não } \\
\text { indicado }\end{array}$ & $\begin{array}{c}\text { Não } \\
\text { indicado }\end{array}$ & $\begin{array}{c}\text { Não } \\
\text { ndicado }\end{array}$ \\
\hline
\end{tabular}

\begin{tabular}{|l|c|}
\hline Não indicado & - \\
\hline Não conclusivo & $+/-$ \\
\hline Indicado & + \\
\hline
\end{tabular}

Fonte: Os autores

O embasamento legal e experiências na administração pública corroboram com as quatro dimensões de fatores críticos encontrados na pesquisa bibliográfica ao levarem em consideração ou citarem tais fatores.

As características das tarefas dos respondentes apontaram para uma possível adaptabilidade ao teletrabalho, por possuirem grande parte dos fatores de sucesso indicados na literatura. Os dados obtidos reforçam a pesquisa de Turetken et al. (2011), quanto aos 
requisitos de independência da tarefa, mensurabilidade das saídas do trabalho e variedade da tarefa.

Quanto às condições de trabalho, a maior parte dos respondentes entende que o ambiente de trabalho é barulhento ou propício à constantes distrações. Estes dados indicam que tarefas que necessitam de alto grau de concentração tenderiam a um possível ganho de produtividade caso fossem executadas remotamente, como indicado por Olson (1983).

Durante a aplicação do instrumento foram verificados fatores apontados por Olson (1983), como a identificação de tarefas mensuráveis e com controle de entregáveis, bem como a necessidade de indicadores de produtividade de todas as tarefas, para adequar às necessidades de mensuração dos resultados, exigida também nos instrumentos regulatórios do teletrabalho na administração pública.

Na pesquisa identificou-se fatores situacionais corroborando com O’Neill et al. (2009) como importantes para a implantação do teletrabalho tendo, como exemplo, a respondente que julga interessante à adoção do teletrabalho pois cuida da mãe de 94 anos, conseguindo assim se dividir entre o trabalho e os cuidados com ela. Vale ressaltar que os fatores situacionais não são conclusivos para o teletrabalho, com alguns autores ressaltando aspectos negativos como possíveis interrupções constantes por membros da família, dentre outros.

O deslocamento ao trabalho foi citado de forma recorrente nas entrevistas como motivação à adoção do teletrabalho, principalmente pela economia de tempo e custo, ratificando o apontamento de Mokhtarian e Salomon (1994 e 1996).

Turetken et al. (2011) destacaram que boas práticas de gerenciamento são fundamentais para o sucesso do teletrabalho, sendo imprescindível um planejamento para sua adoção na instituição, através do mapeamento de processos e definição de indicadores de desempenho para controle dos resultados durante trabalho remoto e presencial, o que ainda não ocorre na maioria dos processos.

Ressalta-se que, num futuro próximo, por avanços tecnológicos ou por modificações nos processos de trabalho, tarefas podem passar a ser adaptáveis à execução remota. Essas modificações de adaptabilidade foram estudadas por Mokhtarian e Salomon (1994 e 1996). $\mathrm{Na}$ pesquisa, um respondente salientou que estava em desenvolvimento uma alteração na forma de execução de suas tarefas, que deixariam de utilizar meios físicos (processos em papel) para utilizar TICs na execução, contribuindo positivamente para a adoção do teletrabalho. Destaca-se que a Instituição está em transição de métodos de trabalho, com 
processos em estágio de mapeamento para migração para o SEI. Esta migração facilitará a adoção do teletrabalho, tanto por informatizar os métodos de execução das tarefas, como por facilitar a criação de indicadores de produtividade.

Recomendam-se as seguintes diretrizes para implantação do teletrabalho na Instituição estudada (Quadro 13):

\section{Quadro 13 - Diretrizes para implantação}

\begin{tabular}{|c|c|}
\hline Diretriz 1 & Adesão ao teletrabalho de forma voluntária pelo servidor. \\
\hline Diretriz 2 & $\begin{array}{r}\text { Obrigatoriedade do servidor participar de treinamento de orientação sobre teletrabalho, } \\
\text { anteriormente ao voluntariado ao programa. Sugere-se temas como descrição das características } \\
\text { pessoais e das tarefas indicadas como favoráveis à adoção deste tipo de trabalho, condições de } \\
\text { trabalho, saúde e segurança dos trabalhadores, informação quanto à necessidade de facilidade ao uso } \\
\text { de tecnologia e responsabilidades pelos investimentos e manutenção da infraestrutura necessária } \\
\text { para teletrabalhar. }\end{array}$ \\
\hline Diretriz 3 & $\begin{array}{r}\text { Sugere-se que sejam incluídos no termo de adesão do servidor a indicação de condições de trabalho } \\
\text { (condiçães ambientais, organização do trabalho, equipamentos, mobiliários) indicadas para não } \\
\text { comprometer a saúde e a segurança do trabalhador e o desempenho da tarefa. }\end{array}$ \\
\hline Diretriz 4 4 & $\begin{array}{r}\text { Preenchimento, pela chefia, em conjunto com o servidor, do método de identificação de tarefas } \\
\text { teletrabalháveis. Sugere-se que o resultado da aplicação do método sirva de base para o } \\
\text { planejamento da adoção do teletrabalho, identificando quais tarefas são adaptáveis ou mais } \\
\text { facilmente adaptáveis, ainda que requeiram pequenas mudanças. }\end{array}$ \\
\hline Diretriz 5 & $\begin{array}{r}\text { Reavaliação do teletrabalho a cada } 6 \text { (seis) meses, para indicação da permanência ou não do } \\
\text { servidor/processo de trabalho no programa. }\end{array}$ \\
\hline Diretriz 6 & $\begin{array}{r}\text { Para a implantação do projeto-piloto na Instituição, sugere-se a utilização do instrumento de suporte } \\
\text { à identificação de adaptabilidade de tarefas e pessoas ao teletrabalho de forma a selecionar pessoas } \\
\text { e tarefas capazes de potencializar as chances de sucesso e possibilitar a conversão do projeto-piloto } \\
\text { em programa de gestão definitivo. }\end{array}$ \\
\hline
\end{tabular}

Fonte: Os autores

Como fatores limitantes do estudo destaca-se que os dados da pesquisa foram alcançados através de amostra por conveniência. Devido ao tempo e movimento grevista ocorrido na instituição, não foi possível realizar mais entrevistas ou mesmo treinar outras pessoas para aplicar o método e contribuir para o aperfeiçoamento dos instrumentos de coleta, análise e classificação. Salienta-se ainda a pequena quantidade de pesquisas brasileiras sobre o tema no setor público, dificultando a comparação com outros trabalhos.

\section{Conclusão}

A pesquisa teve como objetivo identificar fatores que favorecem a implantação bemsucedida do teletrabalho, além da base legal e experiências existentes na administração 
pública brasileira. Para tal, as questões de pesquisa nortearam o estudo, que através da revisão bibliográfica, desenvolveu o método de identificação de tarefas teletrabalháveis, servindo de ferramenta de gestão para a implantação planejada e sistematizada do teletrabalho, considerando as peculiaridades do setor público.

A primeira contribuição está na difusão do tema, que ainda é pouco estudado na administração pública brasileira. Outra contribuição foi fornecer insumos (diretrizes, método e instrumento) para sistematizar o planejamento de mudanças na organização de trabalho na instituição estudada, trazendo o teletrabalho como proposta de flexibilização da jornada de trabalho dos servidores, em consonância com a regulamentação vigente.

O método desenvolvido para identificação de tarefas teletrabalháveis inclui: roteiro estruturado de entrevista presencial para levantamento de informações; conjunto de indicadores, critérios e diretrizes para análise da aderência entre as respostas e os fatores críticos de sucesso para o teletrabalho; instrumento de classificação da situação analisada (pessoa-tarefas), que aponta se há indicação para teletrabalho ou quais as pendências para viabilizar a indicação.

Os resultados indicaram que há a presença de fatores críticos de sucesso para o teletrabalho em atividades realizadas na instituição. Destaca-se que as características das tarefas ficam mais evidentes com a aplicação do método, indicando onde é preciso avançar para favorecer a adaptação ao teletrabalho.

Como continuidade da pesquisa sugere-se investigar formas de avaliação do percentual da jornada a ser executada remotamente, além da análise da aplicabilidade do método desenvolvidos na pesquisa em organizações privadas.

\section{REFERÊNCIAS}

DALLOUL, S. Y. Y.. Teletrabalho no serviço público e a (i)legalidade da exigência de acréscimo de produtividade. Conteúdo Jurídico. 2018. Disponível em:

<http://www.conteudojuridico.com.br/consulta/Artigos/51474/teletrabalho-no-servico-publico-e-a-i-legalidadeda-exigencia-de-acrescimo-de-produtividade>. Acesso em: 20 nov. 2018.

FRITZ, M.; NARASIMHAN, S.; RHEE, H.. Communication and coordination in the virtual office. Journal of Management Information Systems, v. 14, n. 4, 1998. pp.7-28 p.

GARRETT, R. k.; DANZIGER, J. N.. Which Telework? Defining and Testing a Taxonomy of Technology

Mediated Work at a distance. Social Science Computer Review, v. 25, n. 1, 2007. 27-47 p.

Lei 12551/11. Altera o art. 6o da Consolidação das Leis do Trabalho (CLT), aprovada pelo Decreto-Lei no 5.452 , de $1^{\circ}$ de maio de 1943 , para equiparar os efeitos jurídicos da subordinação exercida por meios 
telemáticos e informatizados à exercida por meios pessoais e diretos, Disponível em:

<http://www.planalto.gov.br/ccivil_03/_Ato2011-2014/2011/Lei/L12551.htm〉. Acesso em: 26 jun. 2018.

Lei 13467/17. Altera a Consolidação das Leis do Trabalho (CLT), aprovada pelo Decreto-Lei no 5.452 , de $1^{\circ}$ de maio de 1943, e as Leis nos 6.019, de 3 de janeiro de 1974, 8.036, de 11 de maio de 1990, e 8.212, de 24 de julho de 1991, a fim de adequar a legislação às novas relações de trabalho. Disponível em:

<http://www.planalto.gov.br/ccivil_03/_ato2015-2018/2017/lei/L13467.htm>. Acesso em: 26 jun. 2018.

MINISTÉRIO DO PLANEJAMENTO, DESENVOLVIMENTO E GESTÃO / SECRETARIA DE GESTÃO DE PESSOAS. Instrução Normativa $\mathrm{N}^{\circ}$ 1, de 31 de agosto de 2018. Disponível em:

<http://portal.imprensanacional.gov.br/materia/-/asset_publisher/Kujrw0TZC2Mb/content/id/39382838/do12018-09-03-instrucao-normativa-n-1-de-31-de-agosto-de-2018-39382704>. Acesso em: 20 nov. 2018.

MOKHTARIAN, P. L.; SALOMON, I.. Modeling the choice of telecommuting: setting the context. Environment and Planning A, v. 26, 1994. 749-766 p.

MOKHTARIAN, P. L.; SALOMON, I.. Modeling the choice of telecommuting: 2. A case of the preferred impossible alternative. Environment and Planning A, v. 28, 1996. 1859-1876 p.

MOKHTARIAN, P. L.; SALOMON, I.. Modeling the choice of telecommuting: 3. Identifying the choice set and estimating binary choice models for technology-based alternatives. Environmentand Planning A, v. 28, 1996. 1877-1894 p.

NEUFELD, D. J.; FANG, Y.. Individual, social and situational determinants of telecommuter productivity. Information and Management, v. 42, 2005. 1037-1049 p.

NILLES, J. M.. Traffic reduction by telecommuting: A status review and selected bibliography. Transportation Research Part A: General, v. 22, n. 4,1988. 301-317 p.

OLSON, M.. Remote office work patterns in space and time. Commun ACM, v. 26, n. 3, 1983. 182-187 p.

O'Neill, T. A. et al. Predicting telework success: an exploration of personality, motivational, situational, and job characteristics. New Technology, Work and Employment, v. 24, n. 22009.

PROGRAMA DAS NAÇÕES UNIDAS PARA O DESENVOLVIMENTO (PNUD). Relatório do desenvolvimento humano 2015: o trabalho como motor do desenvolvimento humano. 2015. Disponível em: 〈http://www.br.undp.org/content/dam/brazil/docs/RelatoriosDesenvolvimento/undp-br-hdr_ptBR-2015.pdf>. Acesso em: 30 jun. 2018.

SIMS JR. et al. The Measurement of job characteristics. Academy of management, v. 19, n. 2, 1976. 195-212 p.

STAPLES, D.; HULLAND, J.; HIGGINS, C.. A self efficacy theory explanation for the management of remote workers in virtual organizations. Organization, v. 10, n. 6, 1999. 758-776 p.

TURETKEN, O. et al. An empirical investigation of the impact of individual and work characteristics on telecommuting success. IEEE Transactions on Professional Communication, v. 54, n. 1, 2011. 56-67 p.

WATSON-MANHEIM, M. B.; PIRAMUTHU, S.; NARASIMHAN, S.. Exploratory analysis of factors influencing performance dynamics of telecommuters and traditional office workers. IEEE Transactions on Systems, Man, and Cybernetics - part C, Applications and Reviews, v. 30, n. 2000. 239-251 p. 